\title{
Effect of maternal undernutrition during pregnancy on early ovarian development and subsequent follicular development in sheep fetuses
}

\author{
M. T. Rae ${ }^{1}$, S. Palassio ${ }^{1}$, C. E. Kyle ${ }^{1}$, A. N. Brooks², R. G. Lea ${ }^{3}$, \\ D. W. Miller ${ }^{4}$ and S. M. Rhind ${ }^{1 *}$ \\ ${ }^{1}$ Macaulay Land Use Research Institute, Craigiebuckler, Aberdeen AB15 8QH, UK; \\ ${ }^{2}$ AstraZeneca, Cancer and Infection Bioscience, Alderley Park, Macclesfield, Cheshire SK10 \\ 4TG, UK; ${ }^{3}$ Rowett Research Institute, Bucksburn, Aberdeen AB2 9SB, UK; and ${ }^{4}$ University of \\ Aberdeen, Department of Agriculture and Forestry, Aberdeen AB24 5UA, UK
}

\begin{abstract}
Gonad development in female sheep fetuses is thought to occur in a number of key stages. The aim of this study was to determine the effects of maternal undernutrition, applied at one or more of these critical stages, on fetal ovarian development. Groups of ewes $(n=11-19)$ were fed rations providing either $100 \%$ (high; $\mathrm{H}$ ) or $50 \%$ (low; L) of energy requirements for live weight maintenance during selected 'windows' during gestation. Control ewes ( $\mathrm{HH}$ and $\mathrm{HHH}$ ) were fed the $\mathrm{H}$ ration from mating until they were killed at days 50, $65(\mathrm{HH})$ or $110(\mathrm{HHH})$ of gestation, whereas ewes of other groups were fed the $\mathrm{L}$ ration for the periods between day 0 and day 30 of gestation (LH and LHH), day 31 and day 50 or 65 of gestation (HL and HLH), day 65 and day 110 of gestation (HHL) or day 0 of gestation until the animals were killed (LL and LLL). At day 50 of gestation, there was no effect of nutritional treatment on mean fetal mass but compared
\end{abstract}

with $\mathrm{HH}$ animals, mean fetal ovarian mass was significantly lower in HL $(P<0.05)$ and $L L(P<0.001)$ animals. At day 65 of gestation, there were significantly fewer germ cells $(P<0.05)$ at the resting, diplotene stage of initial meiosis in LL animals than there were in $\mathrm{HH}$ animals, indicating delayed germ cell maturation and onset of meiosis. Qualitative assessment of proliferative cell nuclear antigen immunostaining indicated that, at day $\mathbf{5 0}$ of gestation, staining was located predominantly in the germ cells, whereas by day 65 of gestation, staining was confined predominantly to somatic cells. Undernutrition in each one of these windows was associated with delayed ovarian follicular development $(P<\mathbf{0 . 0 5 - 0 . 0 0 1 )}$ as measured by development of the granulosa cell layer at day 110 of gestation. This study demonstrates that undernutrition before and during folliculogenesis can delay fetal follicular development.

\section{Introduction}

The capacity of prenatal and early postnatal nutrition to affect reproductive function in sheep has been recognized for some time (Gunn et al., 1972; Gunn, 1977; Allden, 1979). More recently, epidemiological studies in humans have indicated that environmental influences, such as nutrition, during fetal development can have effects on the health of the offspring when they are adults (Barker et al., 1992; Barker, 1994); an observation that resulted in the term 'fetal programming'.

Studies by Rhind et al. (1989) and Gunn et al. (1995), using the sheep as an experimental model, showed that undernutrition during early stages of development, either before or after birth, could reduce the lifetime reproductive capacity of the female offspring, as measured by the incidence of barrenness and of multiple births, which in turn were related directly to the numbers of lambs reared.

* Correspondence

Email: s.rhind@mluri.sari.ac.uk
This work stimulated more detailed studies of the underlying physiology (Borwick et al., 1997), which showed that maternal undernutrition during fetal life can influence fetal ovarian development and might therefore alter adult reproductive performance. However, effects of undernutrition may be expressed at many stages of development and the relative importance of each of these stages is unknown. The normal pattern of fetal ovarian development in sheep has been described by McNatty et al. (1995) and Borwick et al. (1997) and has provided information on the timescales of major developmental events. The aim of the present study was to determine the effects on ovarian development in sheep fetuses of maternal undernutrition applied at different, selected stages of pregnancy, including periods of fetal ovarian differentiation (days 0-30 of gestation), ovarian growth (days 31-50 of gestation), ovarian growth and germ cell meiosis (days 31-65 of gestation), and folliculogenesis (days $65-110$ of gestation). Thus, this study was designed to establish the stages of development that are most sensitive to nutrition. 


\section{Materials and Methods}

\section{Animal management and nutritional treatments}

All experimental procedures involving animals were conducted under the authority of the Animals (Scientific Procedures) Act, 1986 after Home Office and local ethical committee approval. Mature Scottish Blackface ewes were fed to achieve similar, moderately high body condition before mating. All ewes were mated at a synchronized oestrus after treatment, for 14 days, with intravaginal progestagen pessaries (Chronolone, $30 \mathrm{mg}$; Intervet, Cambridge). At the time of mating, ewes were allocated randomly within body condition score class (range 2.25-3.00, on a scale of 0-5; Russel et al., 1969) to one of four (Expts 1 and 2) or five (Expt 3) nutritional treatment groups. They were fed rations estimated to supply the metabolizable energy (ME) requirements of a pregnant ewe (high; H), or $50 \%$ of that amount (low; L), according to stage of pregnancy and treatment group (Robinson et al., 1983). The diet comprised pelleted feed (Green Keil, North Eastern Farmers Ltd) and hay, and provided 8.0 MJ ME per day $(\mathrm{H})$ or 4.0 MJ ME per day (L). From the time of mating onwards, sheep were housed individually under natural lighting conditions with access to water ad libitum.

In Expt 3, ewes were scanned, using ultrasonography, at day 80 of gestation to determine the number of fetuses, and rations were then increased as necessary to maintain the same differential nutritional states while the fetal burdens were increasing (Robinson et al., 1983). All ewes were weighed and body condition was scored every 21 days throughout the experiments.

\section{Tissue collection and processing}

Ewes bearing twin or single fetuses were killed by barbiturate overdose (Euthatal, $500 \mathrm{mg} \mathrm{ml}^{-1}, 30 \mathrm{ml}$ i.v.; Rhone Merieux, Harlow) on day 50, 65 or 110 of pregnancy (Expts 1, 2 and 3, respectively). Female fetuses were recovered and weighed. Fetal ovaries were removed, weighed and immersion-fixed in Bouin's solution for $5.5 \mathrm{~h}$. Ovaries were then rinsed in $70 \%$ ethanol and transferred to $70 \%$ ethanol before being dehydrated, cleared and embedded in paraffin wax by standard methods, sectioned to $5 \mu \mathrm{m}$, and mounted on poly-L-lysine-coated glass slides for analysis. In all three experiments, discrepancies between the numbers of ewes in each group and the numbers of fetuses are attributable to the fact that this part of the study concerned only female fetuses.

\section{Experiment 1: ovarian development at day 50 of gestation}

Feeding. Ewes ( $n=15-19$ per group) with a mean live weight $( \pm$ SEM) of $59.0 \pm 0.62 \mathrm{~kg}$ and a mean condition score of $2.46 \pm 0.02$ at mating were housed and fed in individual pens as follows: $\mathrm{HH}$ : live weight maintenance ration $(100 \% \mathrm{M})$ from mating to day 50 of gestation; $\mathrm{LH}$ : $50 \% \mathrm{M}$ from mating to day 30 of gestation and then $100 \% \mathrm{M}$ from day 31 to day 50 of gestation; HL: 100\% M from mating to day 30 of gestation and then $50 \% \mathrm{M}$ from day 31 to day 50 of gestation; LL: $50 \%$ M from mating to day 50 of gestation.

Laboratory procedures. Fetal ovaries were stained immunohistochemically for proliferating cell nuclear antigen (PCNA), as an indicator of proliferative activity, using the method of Murray et al. (2000). Negative control slides were produced by processing sections in an identical fashion, except that the primary antiserum, raised in mice, was replaced with mouse IgG at an identical concentration to that of the primary antiserum.

\section{Experiment 2: ovarian development at day 65 of gestation}

Feeding. Ewes ( $n=12-13$ per group) with a mean live weight of $58.7 \pm 0.82 \mathrm{~kg}$ and a mean body condition score of $2.44 \pm 0.03$ at mating were housed and fed in individual pens according to the same regimen as in Expt 1, except that ewes were killed at day 65 instead of day 50 of gestation, and that the second treatment window of each group was extended accordingly.

Laboratory procedures. Sections (four per ovary, $5 \mu \mathrm{m}$ thick and separated by $5 \mu \mathrm{m}$ ) were stained using the modified Feulgen reaction, and the numbers of meiotic cells were determined (in four $0.25 \mathrm{~mm}^{2}$ fields per section) on the basis of Feulgen pigmentation. Oogonia entering the first phase of meiosis become heavily pigmented in this system and those that have entered meiotic arrest stain only very weakly (Borwick et al., 1997). Ovaries were also subjected to immunohistochemistry to determine PCNA expression and thus proliferative activity.

\section{Experiment 3: ovarian development at day 110 of gestation}

Feeding. Ewes ( $n=11-19$ per group) with a mean live weight of $59.3 \pm 0.74 \mathrm{~kg}$ and a mean body condition score of $2.46 \pm 0.02$ at mating were treated according to the regimens described for Expt 2, except that animals were killed at day 110 of gestation and a third period of undernutrition was applied between day 66 and day 110 of gestation.

Laboratory procedures. From each fetal ovary, ten $5 \mu \mathrm{m}$ sections were cut, $5 \mu \mathrm{m}$ apart, mid-way through the ovary and stained with haematoxylin and eosin; this stain was considered to be the most appropriate for the measurements required. The number of follicles at each developmental stage (four $0.25 \mathrm{~mm}^{2}$ areas per section, each area encompassing the cortex) were counted in each section, including only those follicles cut through the plane of the oocyte nucleus. Thus, if the follicle was not sectioned through the nucleus, it was not counted and so the risk of counting a follicle more than once was eliminated. Follicles were classified according to the system of Lundy et al. (1999). In brief, this classification system was as follows: isolated 

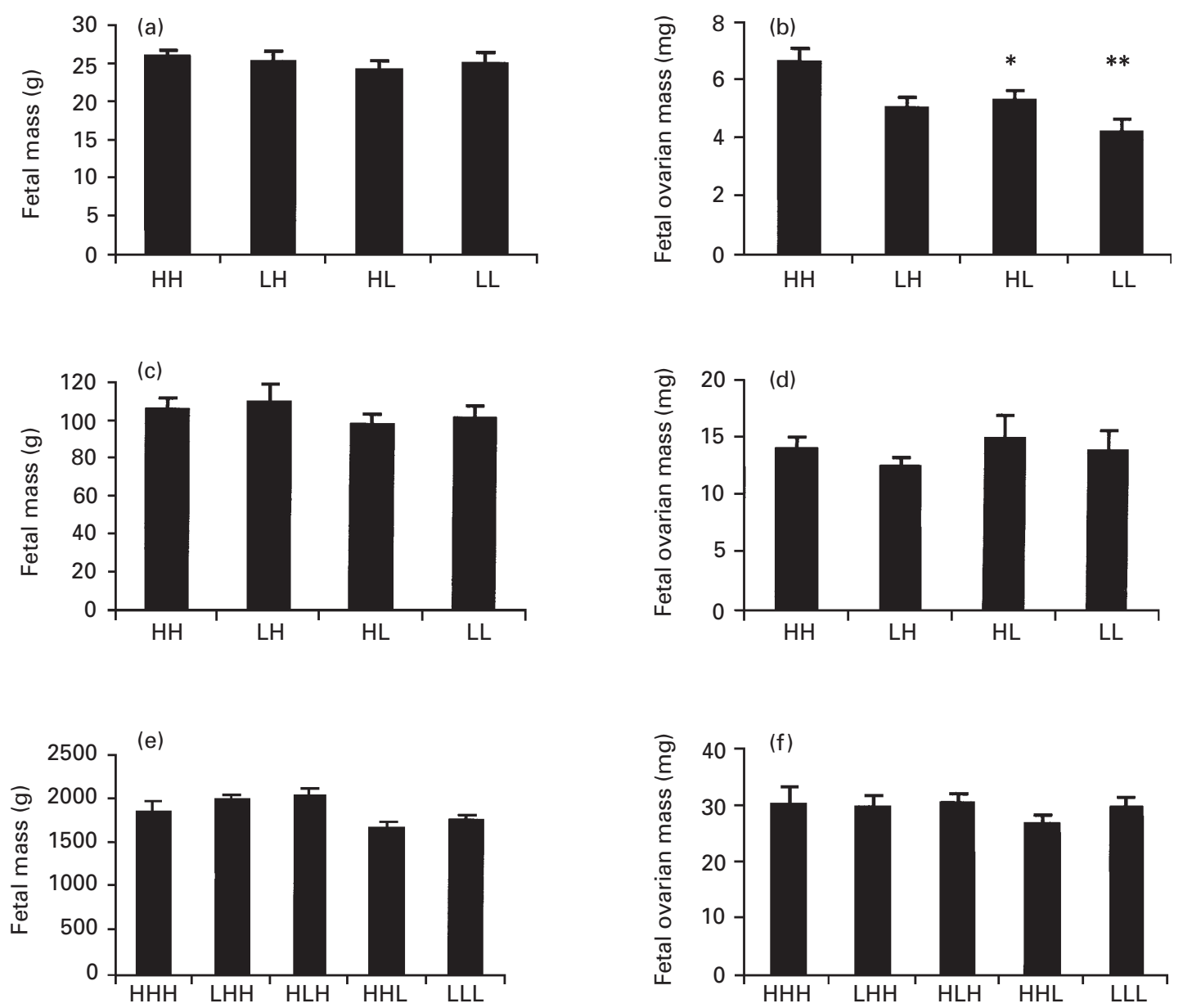

Fig. 1. Effects of maternal undernutrition on mean fetal mass (g) and fetal ovarian mass (mg) in sheep. Results are shown as means \pm SEM. Groups of ewes $(n=11-19)$ were fed rations providing either $100 \%$ (high; $\mathrm{H}$ ) or $50 \%$ (low; L) of energy requirements for live weight maintenance. Control ewes $(\mathrm{HH}$ and $\mathrm{HHH}$ ) were fed the $\mathrm{H}$ ration from mating until they were killed at days 50, $65(\mathrm{HH})$ or $110(\mathrm{HHH})$ of gestation, whereas ewes of other groups were fed the $\mathrm{L}$ ration for the periods between day 0 and day 30 of gestation (LH and LHH), day 31 and day 50 or day 65 of gestation $(\mathrm{HL}$ and $\mathrm{HLH})$, day 65 and day 110 of gestation $(\mathrm{HHL})$ or day 0 of gestation to when the animals were killed (LL and LLL). (a) Fetal masses at day 50 of gestation (Expt 1); (b) fetal ovarian mass at day 50 of gestation (Expt 1); (c) fetal mass at day 65 of gestation (Expt 2); (d) fetal ovarian mass at day 65 of gestation (Expt 2); (e) fetal mass at day 110 of gestation (Expt 3); and (f) fetal ovarian mass at day 110 of gestation (Expt 3). Significant differences relative to $\mathrm{HH}$ control values within experiment: $* P<0.05$; $* * P<0.01$.

oocyte: no granulosa layer; type 1: primordial follicle, one layer of flattened granulosa cells surrounding the oocyte; type 1A: transitory follicle, one layer of a mixture of flattened and cuboidal granulosa cells; type 2: primary follicle, one to fewer than two complete layers of cuboidal granulosa cells; type 3: small preantral follicle, two to fewer than four complete layers of cuboidal granulosa cells; type 4: large preantral follicle, four or five layers of cuboidal granulosa cells; type 5: large follicle, more than five layers of cuboidal granulosa cells and a fully formed antrum.

\section{Statistical analysis}

The effects of treatment and litter size on mean fetal mass, fetal ovarian mass and the number of cells were analysed separately for each experiment by two-way
ANOVA, using specific contrasts between controls and treated groups. Percentages of pigmented oocytes were subjected to angular transformation before ANOVA.

\section{Results}

\section{Experiment 1}

When the animals were killed on day 50 of gestation, the respective mean $( \pm$ SEM) live weights and body condition scores of ewes in each treatment group were $53.9 \pm$ $1.36 \mathrm{~kg}$ and $2.46 \pm 0.06(\mathrm{HH}), 52.7 \pm 1.04 \mathrm{~kg}$ and $2.34 \pm 0.05(\mathrm{LH}), 50.0 \pm 1.10 \mathrm{~kg}$ and $2.28 \pm 0.06(\mathrm{HL})$, and $50.1 \pm 1.12 \mathrm{~kg}$ and $2.28 \pm 0.06(\mathrm{LL})$.

Mean fetal masses were unaffected by treatment (Fig. 1a), but mean fetal ovarian masses were reduced in the HL 
Table 1. Number of germ cells and percentage of total germ cells exhibiting dense Feulgen staining at day 65 of gestation in sheep fetuses from four nutritional treatment groups (Expt 2)

\begin{tabular}{lccrr}
\hline & & \multicolumn{2}{c}{ Nutritional treatment } \\
\cline { 2 - 4 } & HH & LH & HL & LL \\
\hline Number of germ cells per mm ${ }^{2}$ & $24.0 \pm 0.97$ & $27.6 \pm 3.2$ & $29.5 \pm 2.01$ & $26.3 \pm 2.46$ \\
Percentage of Feulgen-positive germ cells & $21.2 \pm 1.19$ & $24.0 \pm 6.3$ & $19.1 \pm 1.45$ & $45.4 \pm 1.92^{*}$ \\
\hline
\end{tabular}

Values are mean \pm SEM.

Groups of ewes ( $n=11-19$ ) were fed rations providing either 100\% (high; H) or 50\% (low; L) of energy requirements for live weight maintenance. Control ewes $(\mathrm{HH})$ were fed the $\mathrm{H}$ ration from mating until they were killed at day 50 or $65(\mathrm{HH})$ of gestation, whereas ewes of other groups were fed the $\mathrm{L}$ ration for the periods between day 0 and day 30 of gestation $(\mathrm{LH})$, days 31 and 50 or 65 of gestation (HL), or day 0 of gestation until they were killed (LL).

*Significantly different compared with $\mathrm{HH}$ values $(P<0.05)$.

$(P<0.05 ; n=13)$ and LL $(P<0.01 ; n=10)$ groups compared with those of the $\mathrm{HH}$ group $(n=12)$, and there was a similar trend in LH fetuses $(n=11)$ (Fig. 1b). No effect of litter size on mean fetal mass and no interaction between treatment and litter size were detected.

Qualitative assessment of PCNA immunostaining indicated that stain was mainly confined to the germ cells (Fig. 2a), as identified by their round appearance and large size. However, although many cells could be classified with certainty as germ cells or somatic cells, there were others that could not be assigned to either category with confidence. Consequently, no attempt was made to quantify the staining of germ cells with respect to treatment.

\section{Experiment 2}

When the animals were killed on day 65 of gestation, the respective mean $( \pm$ SEM) live weights and body condition scores in each treatment group were $54.5 \pm 1.96 \mathrm{~kg}$ and $2.45 \pm 0.06(\mathrm{HH}), 54.2 \pm 1.05 \mathrm{~kg}$ and $2.40 \pm 0.04(\mathrm{LH})$, $51.8 \pm 1.94 \mathrm{~kg}$ and $2.40 \pm 0.06(\mathrm{HL})$, and $49.9 \pm 1.07 \mathrm{~kg}$ and $2.31 \pm 0.03(\mathrm{LL})$.

No significant effects of treatment or litter size on mean fetal masses or mean fetal ovarian masses were detected at this time ( $\mathrm{HH}, n=8 ; \mathrm{LH}, n=7 ; \mathrm{HL}, n=8 ; \mathrm{LL}, n=6$ fetuses) (Fig. 1c and d, respectively) and no significant interaction was detected between them.

Although no significant differences in the total number of germ cells were recorded, fewer germ cells $(P<0.05)$ were found at the resting, diplotene stage of initial meiosis in LL fetal ovaries than in $\mathrm{HH}$ fetuses (Table 1).

Qualitative immunohistochemistry for PCNA indicated that staining was mainly confined to somatic cells and was not detected in most germ cells (Fig. 2b).

\section{Experiment 3}

When the animals were killed on day 110 of gestation, the respective mean ( \pm SEM) live weights and body condition scores in each treatment group were $62.37 \pm$ $1.99 \mathrm{~kg}$ and $2.41 \pm 0.04(\mathrm{HHH}), 62.3 \pm 1.66 \mathrm{~kg}$ and $2.38 \pm 0.03(\mathrm{LHH}), \quad 61.6 \pm 1.85 \mathrm{~kg}$ and $2.32 \pm 0.06$
$(\mathrm{HLH}), \quad 55.6 \pm 1.46 \mathrm{~kg}$ and $2.20 \pm 0.04(\mathrm{HHL})$, and $48.7 \pm 1.34 \mathrm{~kg}$ and $1.93 \pm 0.05$ (LLL).

No significant effects of treatment or litter size on mean fetal masses or mean fetal ovarian masses were detected $(\mathrm{HHH}, n=7 ; \mathrm{LHH}, n=9 ; \mathrm{HLH}, n=12 ; \mathrm{HHL}, n=11 ; \mathrm{LLL}$, $n=16$ fetuses) (Fig. $1 \mathrm{e}$ and $\mathrm{f}$, respectively) and no significant interaction was detected between them.

Although the mean total number of oocytes was unaffected by treatment (Fig. 3g), nutritional restriction in each period of gestation (LHH, HLH, HHL and LLL groups) was associated with a significant reduction in the numbers of follicles beyond the primordial stage $(P<0.05)$. In addition, HHL ovaries had a significantly higher number of isolated oocytes than did control ovaries or ovaries from other treatment groups $(P<0.05)$ (Fig. 3). No type 5 follicles were detected in any of the ovaries studied.

\section{Discussion}

Although several epidemiological studies have used birth weight as an index of nutrition during human pregnancy, as noted by Lumey (1998), effects of fetal undernutrition on subsequent health are not necessarily associated with birth weight, probably because the critical window of development during which the fetus is sensitive to nutrition occurs before measurable effects on fetal mass are expressed. To date, the only demonstration of impaired ovarian development in humans as a result of restricted nutrition has been in cases of intrauterine growth retardation owing to placental insufficiency (de Bruin et al., 1998). The results of the present study provide clear evidence that effects of undernutrition on ovarian development can occur independently of any consistent effects on fetal mass.

The earliest period of underfeeding imposed in this study, days 0-30 of gestation, could affect only germ and somatic cells of the ovarian-mesonephros complex as granulosa cells are not present at this stage of development in sheep fetuses (McNatty et al., 1995). However, there may be effects on the parent cell populations that give rise to the granulosa cells and other ovarian somatic types of cell. 

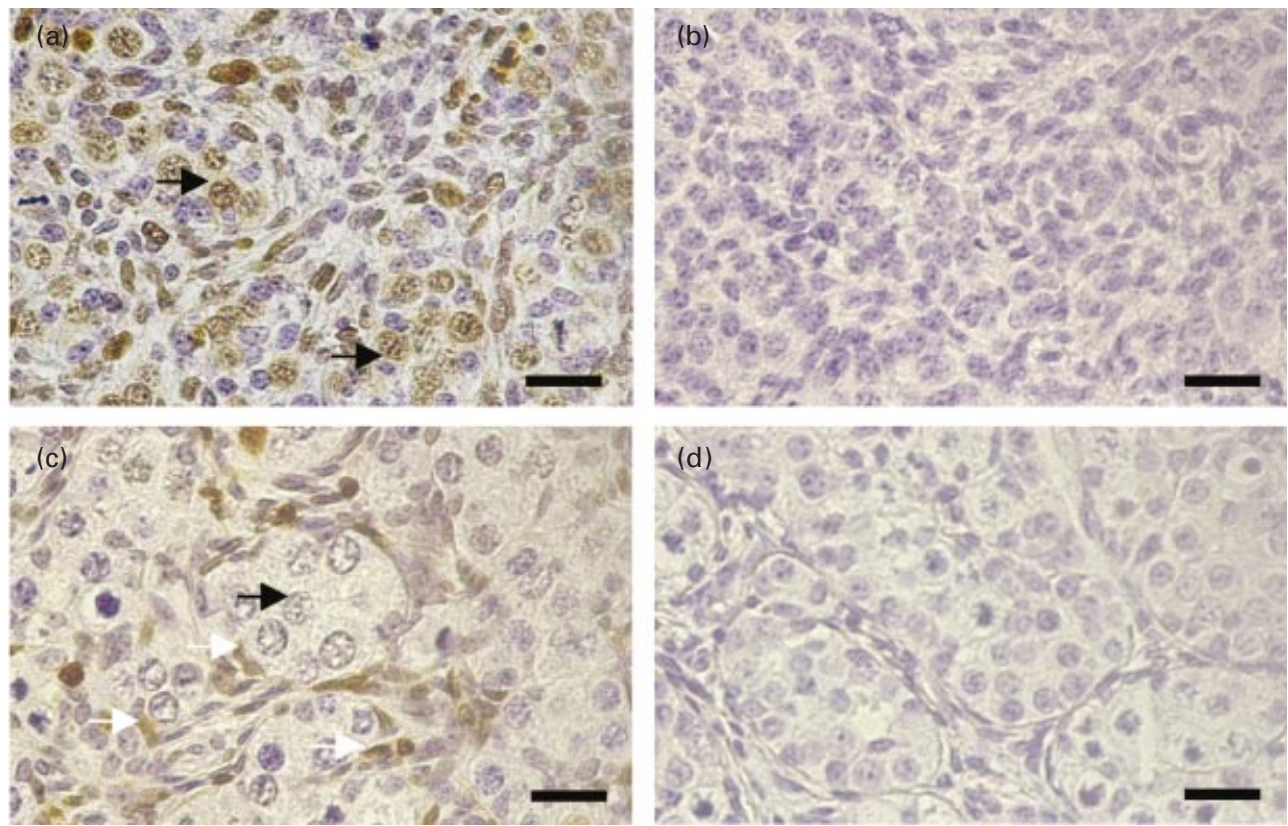

Fig. 2. Immunohistochemistry for proliferating cell nuclear antigen (PCNA) in the ovaries of sheep fetuses at day 50 of gestation (a, Expt 1) and day 65 of gestation (c, Expt 2); (b) and (d) are representative IgG negative control sections for (a) and (c), respectively. Most immunopositive cells at day 50 of gestation are germ cells, identified by round appearance, whereas by day 65 of gestation, most immunopositive cells are ovarian somatic cells located in cell streams surrounding nests of oogonia. Black arrows indicate oogonia; white arrows indicate somatic cells. Scale bars represent $20 \mu \mathrm{m}$.

Undernutrition between day 0 and day 30 of gestation had no significant effects on ovarian mass or gross morphology at any of the times studied. However, at day 110 of gestation, there were significantly more type 1 primordial follicles, and a concomitant reduction in the numbers of type 2, 3 and 4 follicles in the ovaries of fetuses subjected to undernutrition from day 0 to day 30 of gestation, indicating that undernutrition imposed before differentiation of the ovary from the mesonephros can compromise subsequent follicular development.

Although undernutrition imposed during the first 30 days of gestation had no significant effect on ovarian mass at day 50 of gestation, undernutrition from day 0 to day 50 or from day 30 to day 50 of gestation (that is, during ovarian development after differentiation) significantly reduced ovarian mass. Collectively, these results indicate that undernutrition affects gross structural development only after day 30 of gestation. As this reduction in ovarian mass was not observed at day 65 of gestation, it appears that there was compensatory growth between day 50 and day 65 of gestation.

As there were no differences in the total numbers of oogonia at day 65 of gestation, or of oocytes at day 110 of gestation, the inability to assess the number of germ cells at day 50 of gestation, during a period of active proliferation and degeneration, may be unimportant and measures of the stage of physiological development may be more relevant. One important physiological development, the onset of oogonial meiosis, occurs in sheep fetuses between day 50 and day 65 of gestation (Borwick et al., 1997). Germ cell proliferation may be expected to cease before the onset of meiosis, and PCNA immunostaining clearly demonstrated a switch from predominantly germ cell proliferation at day 50 of gestation to predominantly somatic cell proliferation during the period up to day 65 of gestation. However, given that germ cell atresia is ongoing at this time, the net cell proliferation:cell atresia ratio may be of more importance than observation of proliferation alone. At day 65 of gestation, during the initial ovarian meiotic period, a significantly larger proportion of germ cells in ovaries from fetuses undernourished from mating to day 65 of gestation were entering the initial stages of meiosis (Expt 2, LL) compared with all other groups, in which most germ cells had completed this initial stage and were in meiotic arrest. This result confirms and extends the findings of Borwick (1997), who observed a similar delay in the onset of meiosis in response to undernutrition. However, the present study demonstrated that this effect was induced only by maternal undernutrition during both periods (days $0-30$ and days 31-65 of gestation), indicating that a combination of feed restriction before and during formation of the ovary was required. This conclusion, in turn, indicates that multiple mechanisms, operating at different stages of development, may be required to induce such effects. Furthermore, as the expression of this effect required undernutrition from day 0 to day 30 of gestation, it is possible that changes are 

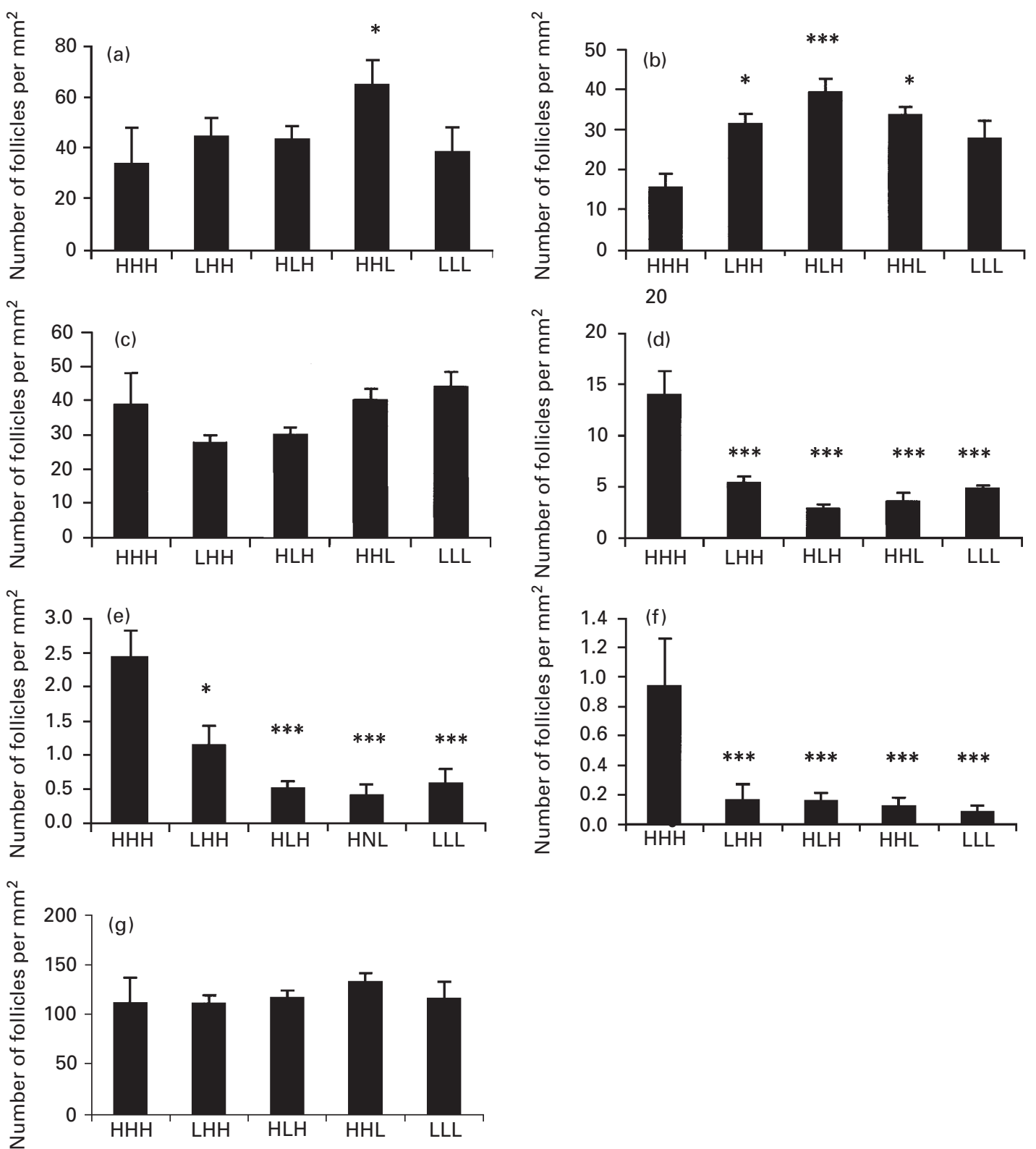

Fig. 3. Effects of maternal undernutrition on the number of ovarian follicles at each stage of development in sheep fetusus at day 110 of gestation. Results are shown as mean numbers of follicles per $\mathrm{mm}^{2} \pm$ SEM. Groups of ewes $(n=11-19)$ were fed rations providing either $100 \%$ (high; $\mathrm{H}$ ) or $50 \%$ (low; L) of energy requirements for live weight maintenance. Control ewes $(\mathrm{HHH})$ were fed the $\mathrm{H}$ ration from mating until they were killed at day $110(\mathrm{HHH})$ of gestation, whereas ewes of other groups were fed the $\mathrm{L}$ ration for the periods between day 0 and day 30 of gestation $(\mathrm{LHH})$, day 31 and day 65 of gestation $(\mathrm{HLH})$, day 65 and day 110 of gestation (HHL) or day 0 of gestation and when the animals were killed (LLL). (a) Number of isolated oocytes (no granulosa layer); (b) type 1 follicles; (c) type $1 \mathrm{~A}$ follicles; (d) type 2 follicles; (e) type 3 follicles; ( $\mathrm{f}$ ) type 4 follicles; and (g) total number of oocytes counted from all follicle classes and isolated oocytes. Significant differences relative to HHH controls within experiment: $* P<0.05,{ }^{* * *} P<0.001$.

mediated through effects on the germ cells, which in sheep fetuses are found in the gonad by about day 35 of gestation (McNatty et al., 2000).

The effects of this difference in the timing of meiosis on oocyte quality have not been assessed, although it has been suggested that oogonia entering meiosis later have a poorer chance of survival (Gondos, 1978). However, the lack of difference in the total number of oocytes in the LLL (undernutrition from day 0 to day 110 of gestation) and $\mathrm{HHH}$ (no feed restriction) groups at day 110 of gestation (Expt 3) indicates that there was no effect of undernutriton on oocyte survival rate. 
As reported in previous studies of fetuses at day 120 of gestation (Lundy et al., 1999), follicles of types 1-4 were present in ovaries at day 110 of gestation. No type 5 follicles were observed, as the earliest stage that such advanced follicles appear in the ovary of sheep fetuses is approximately day 135 of gestation (Lundy et al., 1999).

Undernutrition imposed during each of the gestational periods reduced the incidence of follicle development beyond the primordial stages at day 110 of gestation (types 1-1A) compared with controls $(\mathrm{HHH})$. Although the total numbers of oocytes were similar in all groups, undernutrition from day 0 to day 30 , from day 30 to day 65 or from day 65 to day 110 of gestation was associated with more type 1 follicles at day 110 than in control fetuses, indicating that the transition from primordial to early primary follicles had been inhibited.

The number of isolated oocytes observed in fetuses from ewes undernourished between day 65 and day 110 of gestation $(\mathrm{HHL})$ was significantly higher than that in control fetuses. This observation, together with the observation that underfeeding from day 0 to day 110 of gestation (LLL) had no effect on the number of isolated oocytes, or the number of type 1 follicles, is indicative of differences in the response to maternal feed restriction between fetal ovaries that have developed in a feed-restricted environment from conception onwards and those derived from ewes subjected to feed restriction after development in a normal environment. Although the degree to which follicle development beyond primordial stages was retarded in the HLH group was similar to that of fetuses of other treatment groups, $\mathrm{HLH}$ fetuses exhibited the greatest increase in the number of type 1 follicles, and the greatest decrease in the number of type 2 follicles, relative to control fetuses. These findings indicate that a window of maximum sensitivity to undernutrition begins between conception and day 65 of gestation and that fetuses exposed to maternal undernutrition during the latter part of this period are more sensitive than those exposed during the earlier period. It was not possible, with the present experimental design, to quantify the patterns of nutrient delivery to the fetuses at each stage of development or to assess the nutrient requirements of the developing placenta. The demands of the placenta may mean that the nutrient supply to the fetus is not related directly to maternal feed intake and this possibility needs to be taken into account when addressing the mechanisms through which the observed effects are mediated.

Many of the effects on fetal ovarian structure reported in this study are expressed before the fetal pituitary contains both $\alpha$ and $\beta$ gonadotrophin subunits (Thomas et al., 1993). In addition, studies of the ovaries of sheep fetuses between day 90 and day 135 of gestation have been unable to detect receptors for FSH or LH (McNatty et al., 2000). Therefore, it seems unlikely that changes in fetal pituitary function play a major role in the mediation of effects of undernutrition on fetal ovarian development.

As development from primordial to primary follicles in sheep fetuses does not commence until about day 90 of gestation (McNatty et al., 2000), maternal undernutrition before day 90 must exert its effects via a mechanism present at this time that affects follicular growth at a later stage of fetal development. Some of the observed effects may be mediated via the germ cell or oocyte. Germ cells in fetal ovaries control a range of aspects of somatic cell development and function (McLaren, 2000) and there is evidence that the oocyte has a role in the control of folliculogenesis. Potential mediators of this oocyte-driven control of folliculogenesis are the germ cell c-kit tyrosine kinase cascade, activated by stem cell factor 1(SCF) (Lundy et al., 1999). SCF is expressed by granulosa cells, and c-kit by oocytes as they become associated with granulosa cells during meiosis (Braw-Tal and Yossefi, 1997). Deletion of growth differentiation factor 9 gene (GDF9), a member of the transforming growth factor $\beta$ super-family expressed by the oocyte, results in failure of follicles to progress beyond the stage of one granulosa layer and limitation of the meiotic ability of the ovaries (Dong et al., 1996). These observations support the suggestion made in the present study that effects mediated at the oocyte may be evident only at later stages of development. It will be of interest to examine the possible involvement of such ooctye-mediated systems in this nutritional model in future experiments.

In conclusion, maternal feed restriction caused a delay in fetal ovarian development in sheep. This effect was not limited to cells and tissues present only during the period of underfeeding, indicating that a nutritional challenge imposed at an early stage of fetal development can have effects at later stages. The consequences of these fetal effects on adult reproductive performance and their mechanisms of action warrant further investigation.

The authors wish to acknowledge the Scottish Executive Environment and Rural Affairs Department (SERAD) for financial support of this work, the staff of Glensaugh Research Station for their technical assistance and Biomathematics and Statistics, Scotland for advice on experimental design and analysis.

\section{References}

Allden WG (1979) Undernutrition of the Merino sheep and its sequelae 5. The influence of severe growth retardation during early post-natal life on reproduction and growth in later life Australian Journal of Agricultural Science 30 939-948

Barker DJP (1994) Mothers, Babies and Diseases in Later Life p. 180. British Medical Journal Publishing Group, London

Barker DJP, Bull AR, Osmond C and Simmonds SJ (1992) Fetal and placental size and risk of hypertension in adult life. In Fetal and Infant Origins of Adult Disease pp 175 -194 Ed. DJP Barker. British Medical Journal Publishing Group, London

Borwick SC, Rhind SM, McMillen SR and Racey PA (1997) Effect of undernutrition of ewes from the time of mating on fetal development in mid gestation Reproduction, Fertility and Development 9 711-715

Braw-Tal R and Yossefi S (1997) Studies in vivo and in vitro on the initiation of follicle growth in the bovine ovary Journal of Reproduction and Fertility 109 165-171

Brooks AN and Thomas GB (1995) Ontogeny and function of the pituitary-gonadal axis during fetal development in sheep Reproduction in Domestic Animals 30 158-162

de Bruin JP, Dorland M, Bruinse HW, Spliet W, Nikkels PGJ and Te Velde 
ER (1998) Fetal growth retardation as a cause of impaired ovarian development Early Human Development 51 39-46

Dong J, Albertini DF, Nishimori K, Kumar TR, Lun N and Matzuk M (1996) Growth differentiation factor-9 is required during early ovarian folliculogenesis Nature $\mathbf{3 8 3} 531-535$

Gondos B (1978) Oogonia and oocytes in mammals. In The Vertebrate Ovary pp 83-120 Ed. RE Jones. Plenum Press, London

Gunn RG (1977) The effects of two nutritional environments from 6 weeks prepartum to 12 months of age on lifetime performance and reproductive potential of Scottish Blackface ewes in two adult environments Animal Production 25 155-164

Gunn RG, Doney JM and Russel AJF (1972) Embryo mortality in Scottish Blackface ewes as influenced by body condition at mating and by postmating nutrition Journal of Agricultural Science, Cambridge 79 19-25

Gunn RG, Sim D and Hunter EA (1995) Effects of nutrition in utero and in early life on the subsequent lifetime reproductive performance of Scottish Blackface ewes in two management systems Animal Science 60 223-230

Lumey LH (1998) Reproductive outcomes in women prenatally exposed to undernutrition: a review of findings from the Dutch famine birth cohort Proceedings of the Nutrition Society 57129-135

Lundy T, Smith P, O'Connell A, Hudson NN and McNatty KP (1999) Populations of granulosa cells in the sheep ovary Journal of Reproduction and Fertility 115 251-262

McLaren A (2000) Germ and somatic cell lineages in the developing gonad Molecular and Cellular Endocrinology 163 3-9

McNatty KP, Smith P, Hudson N, Heath D, Tisdall DOW and Brawtal R (1995) Development of the sheep ovary during fetal and early neonatal life and the effect of fecundity genes Journal of Reproduction and Fertility 49 123-135

McNatty KP, Fidler AE, Juengel JL, Quirke LD, Smith PR, Heath DA, Lundy T, O'Connel A and Tisdall DJ (2000) Growth and paracrine factors regulating follicular formation and cellular function Molecular and Cellular Endocrinology 163 11-20

Murray TJ, Fowler PA, Abramovich DR, Haites N and Lea RG (2000) Markers of development and endocrine function in the human fetal testis Journal of Endocrinology and Metabolism 85 4812-4817

Rhind SM, McKelvey WAC, McMillen SR, Gunn RG and Elston DA (1989) Effect of restricted food intake, before and/or after mating, on the reproductive performance of greyface ewes Animal Production 48 149-155

Robinson JJ, Russel AJF, Treacher TT, Kilkenny JB (1983) Feeding the Ewe Meat and Livestock Commission Sheep Improvement Services pp 1-60

Russel AJF, Doney JM and Gunn RG (1969) Subjective assessment of body fat in live sheep Journal of Agricultural Science, Cambridge 72 451-454

Thomas GB, McNeilly AS and Brooks AN (1993) Development of gonadotrophs and thyrotrophs in the female fetal sheep pituitary: immunocytochemical localization studies Journal of Neuroendocrinology 5 157-161

Received 21 March 2001.

First decision 4 June 2001.

Accepted 4 September 2001. 